\title{
AVALIAÇÃO CLINICA DO USO DA DECAMETRINA NO TRATAMENTO DA PEDICULOSE DO COURO CABELUDO
}

Newton Mamoru Sasaki* José Rubens Barbosa Cortez**

SASAKI, N.M. \& CORTEZ, J.R.B. Avaliação clínica do uso da decametrina no tratamento da pediculose do couro cabeludo. Rev. Saúde públ., S. Paulo, 19:300-3, 1985.

RESUMO: A decametrina, um inseticida piretróide sintético, foi avaliada no tratamento da infestação por Pediculus humanus capitis em 54 crianças. Foi empregada emulsão a $0,0025 \mathrm{mg} / \mathrm{ml}$ da decametrina em tratamento tópico único ou repetido após 8 dias, se ainda persistissem sinais do Pediculus humanus capitis. O resultado após o $16 .^{\circ}$ dia do tratamento foi considerado satisfatório em $98,2 \%$ dos casos observados, sendo que 28 crianças, $47,4 \%$ dos casos, não apresentaram nenhum sinal de infestação $e$ os demais apresentaram lêndeas secas, em sua maioria e, portanto, inviáveis. A toxicidade foi avaliada pelo exame clínico nos indivíduos tratados e nos aplicadores, não sendo constatadas alterações tróficas locais ou à distância no exame clínico, nem ocorrido queixas. Pela eficácia apresentada, pela ausência de toxicidade e pelo baixo custo do tratamento, concluiu-se pela grande aplicabilidade da decametrina no controle da infestação por Pediculus humanus capitis, em nosso meio.

UNITERMOS: Pediculose, terapia. Decametrina. Piretróides.

\section{INTRODUÇÃO}

A pediculose do couro cabeludo vem recentemente tomando importância como uma das ectoparasitoses que mais preocupam os responsáveis pela saúde da criança na faixa etária dos 2 aos 8 anos, no Estado de São Paulo.

São múltiplos os fatores implicados na disseminação do parasita nesse grupo etário, sendo lembrado, mais freqüentemente, a irregularidade dos hábitos de higiene corporal, a intimidade do relacionamento entre eles principalmente no ambiente escolar e a resistência aos agentes habitualmente empregados no tratamento: lindano, benzoato de benzila e monossulfiram ${ }^{3,6}$.

Estudando a solução que vem sendo adotada em outros países, notamos o uso dos piretróides nos Estados Unidos da América e, particularmente, da decametrina, na Argentina ${ }^{1,2,5}$.

A decametrina no Brasil é usada como carrapaticida empregada em veterinária, e apresenta, comparativamente aos demais inseticidas, as seguintes vantagens: grande poder pediculicida tanto para o parasita adulto como para seu ovo, baixa toxicidade, geralmente é de única aplicação, é missível em água, não tem cor, seu odor não é repugnante e é de baixo custo.

Considerando ainda o suprimento irregular de pediculicidas nas unidades da Secretaria da Saúde do Estado de São Paulo, propusemo-nos, no estudo presente, a avaliar a aplicabilidade, eficácia e tolerabilidade da decametrina no controle da pediculose como alternativa

\footnotetext{
- Do Centro de Saúde I de Tatuí da Secretaria Saúde do Estado de Sảo Paulo - Praça Adelaide Guedes, s/n. $0^{\circ}$ - 18.270 - Tatui, SP - Brasil.

* Do Centro de Saúde de Votorantim, da Secretaria da Saúde do Estado de São Paulo - 18.110 Votorantim, SP - Brasil.
} 
SASAKI, N.M. \& CORTEZ, J.R.B. Avaliação clínica do uso da decametrina no tratamento da pediculose do couro cabeludo. Rev. Saúde públ., S. Paulo, 19:300-3, 1985.

aos preparados existentes no mercado farmacêutico.

\section{MATERIAL E METODOS}

Foi empregada a decametrina, em emulsão de $0,0025 \mathrm{mg} / \mathrm{ml}$, obtida no comércio local com a designação de fantasia de Butox-P, produzida pelo laboratório Quimio S/A, licença do Ministério da Agricultura n. ${ }^{\circ} 1.428$.

Este produto é apresentado em ampolas de $10 \mathrm{ml}$ que contém $50 \mathrm{mg}$ de decametrina que foi diluída com água q.s.p. 20 litros (esta diluição oferece a emulsão de $0,0025 \mathrm{mg} / \mathrm{ml}$ da decametrina utilizada).

O tratamento foi realizado em crianças do Recanto Betel de Tatuí, onde elas são atendidas em regime de semiinternato, isto é, das 8 às 17 horas de segunda a sexta-feira.

As crianças examinadas foram divididas em grupos de portadores do ectoparasita vivo adulto, portadores de ovos viáveis (lêndeas) do parasita e aqueles sem sinais da infestação.

As crianças infestadas foram tratadas com a emulsão da decametrina, sendo esta friccionada no couro cabeludo sem lavagem prévia do cabelo, tendo-se a precaução de não atingir com o inseticida os olhos e a face. A remoção do medicamento ocorreu após 24 horas da aplicação, com lavagem do couro cabeludo com água e sabonete comum.

Realizaram-se exames clínicos subsequientes às 24 e 48 horas após a aplicação com a finalidade principal de detectar-se sinais de intoxicação aguda à aplicação tópica da decametrina.

Novos exames clínicos foram realizados no $8 .^{\circ}$ e $16 .^{\circ}$ dias após o tratamento com a finalidade de avaliar-se a evolução da ectoparasitose e assim inferir-se a eficácia do tratamento, além de avaliar-se a toxicidade. Em havendo sinais do Pediculus humanus capitis no $8 .^{\circ}$ dia, foi realizada uma segunda aplicação da emulsão de decametrina.

\section{RESULTADOS}

Cinqüenta e nove crianças foram examinadas, todas da faixa etária de 2 a 6 anos de idade. Trinta e sete eram do sexo feminino.

Como mostra a Tabela 1,54 apresentavam sinais da ectoparasitose, sendo que 21 apresentavam parasitas adultos e lêndeas, e 33 apenas lêndeas viáveis. A distribuição da infestação segundo o sexo apresentou diferenças de proporções não significantes: entre as meninas 35 eram infestadas e 2 não, e entre os meninos 19 eram infestados e 3 não.

\section{TABELA 1}

Distribuição das infestações por Pediculus humanus capitis segundo o sexo nas crianças do Recanto Betel de Tatuí, maio de 1984.

\begin{tabular}{|c|c|c|c|c|c|c|}
\hline \multirow{2}{*}{$\begin{array}{l}\text { Sinais da } \\
\text { Ectoparasitose }\end{array}$} & \multicolumn{2}{|c|}{ Feminino } & \multicolumn{2}{|c|}{ Masculino } & \multicolumn{2}{|c|}{ Total } \\
\hline & $\mathbf{n}$ & $(\%)$ & $\mathbf{n}$ & $(\%)$ & $\mathbf{n}$ & $(\%)$ \\
\hline Parasitas adultos e lêndeas & 16 & (43) & 5 & (23) & 21 & (35) \\
\hline Apenas lêndeas & 19 & (51) & 14 & (64) & 33 & (56) \\
\hline Ausentes & 2 & (6) & 3 & (13) & 5 & (9) \\
\hline Total & 37 & $(100)$ & 22 & $(100)$ & 59 & $(100)$ \\
\hline
\end{tabular}

$x^{2}=6,57(2 \mathrm{Gl}.) \mathrm{p}>0,05$ 
SASAKI, N.M. \& CORTEZ, J.R.B. Avaliação clínica do uso da decametrina no tratamento da pediculose do couro cabeludo. Rev. Saúde públ., S. Paulo, 19:300-3, 1985.

E importante realçar-se a grande proporção de indivíduos infestados, $91,6 \%$ da população sob investigação.

$O$ resultado do tratamento observado no $8 .^{\circ}$ dia após a aplicação foi de 14 casos onde desapareceu a ectoparasitose, e nenhuma das crianças nesse exame apresentou parasita adulto, sendo detectadas lêndeas em 40 crianças, e nestas foi repetido o tratamento com a decametrina.

O resultado do segundo tratamento foi de mais 10 crianças sem nenhum sinal de ectoparasitose, e de 29 onde persistiram as lêndeas, só que estas eram secas em sua maioria, e portanto inviáveis, e também facilmente removidas dos cabelos.

$\mathrm{Na}$ avaliação do $16^{\circ}$ dia foi notada uma criança com reinfestação, pois apresentava parasita adulto novamente.

Em nenhum dos exames realizados foi constatado qualquer sinal ou sintoma de efeito tóxico local ou à distância da decametrina e sua aceitabilidade foi boa.

\section{COMENTÁRIOS}

Os resultados mostram um efeito favorável em $98,2 \%$ dos casos observados, sendo a ausência do parasita constatada em 28 casos $(47,4 \%)$ e a persistência das lêndeas em $30(50,8 \%)$. Mesmo esta persistência após o $16 .^{\circ}$ dia do tratamento foi considerada como resultado favorável ao tratamento, pois as lêndeas eram agora secas, em sua maioria, portanto inviáveis, demonstrando o efeito ovicida da decametrina.

A presença de crianças com cabelos compridos, os quais não foram cortados, pois grande parte o eram por motivos religiosos, foi considerado como um grau de dificuldade maior na remoção das lêndeas.

A aplicação da decametrina foi considerada sem reações adversas tanto pelos indivíduos tratados como pelos aplicadores; duas pessoas mantiveram-se expostas à decametrina por pelo menos 2 horas em cada seção de aplicação.

Em comparação com as demais preparações existentes no mercado, o uso da decametrina foi considerado mais favorável, não só pelas suas características físico-químicas como também porque na maioria dos casos uma aplicação isolada foi suficiente como tratamento.

$E$ importante lembrar que lamentavelmente o tratamento não foi acompanhado de um trabalho educativo de colaboração dos pais ou responsáveis. A higiene local e a remoção mecânica das lêndeas e parasitas adultos com pentefino, ou manualmente, elevaria ainda mais a proporção de ausência de sinais da ectoparasitose e previniria a reinfestação com parasitas adultos, como ocorreu com um caso nesta observação.

$\mathrm{Na}$ Tabela 2 estão apresentados o custo por mililitro dos diversos medicamentos disponíveis no mercado farmacêutico brasileiro, na forma líquida. Observa-se a posição altamente favorável à decametrina cujo custo chega a ser 100 vezes menor que o produto mais barato disponível no mercado.

\section{TABELA 2}

Preço por mililitro dos diversos produtos farmacêuticos disponíveis no mercado brasileiro na forma líquida, indioados para o tratamento da pediculose, e considerado o produto de menor preço, comparado ao preço por mililitro da emulsão da decametrina empregada nesta observação, agosto de 1984.

\begin{tabular}{lc}
\hline Substância ativa & preço Cr\$ / ml \\
\hline Benzoato de benzila & 13,05 \\
Lindano & 14,09 \\
Monossulfiram & 26,87 \\
Decametrina & 0,12 \\
\hline
\end{tabular}

Fonte: Brasíndice, ed. agosto de 1984, exceto para decametrina calculado para o produto Butox-P, Laboratório Quimio S/A, adquirido no comércio local. 
SASAKI, N.M. \& CORTEZ, J.R.B. Avaliação clínica do uso da decametrina no tratamento da pediculose do couro cabeludo, Rev. Saúde públ., S. Paulo, 19:300-3, 1985.

\section{CONCLUSÃO}

Considerando-se a importância da pediculose como problema de saúde emergente em creches e escolas de primeiro grau, a resistência dos preparados usualmente empregados, os elevados custos dos mesmos em comparação à decame- trina, e a eficácia e baixa toxicidade desta, observada neste trabalho e corroborada por Patrús e col. ${ }^{6}$, acreditamos ser a decametrina opção importante no controle das infestações por Pediculus humanus capitis em nosso meio.

SASAKI, N.M. \& CORTEZ, J.R.B. [A clinical evaluation of the use of decamethrin in the treatment of pediculus of the scalp]. Rev. Saúde públ., S. Paulo, 19:300-3, 1985.

ABSTRACT: Fifty four children showing Pediculus humanus capitis infestation were treated with decamethrin, a synthetic pyrethoid inseticide. Decamethrin emulsion of $0.0025 \mathrm{mg} / \mathrm{ml}$ was used in a single topical treatment or repeated if the infestation signs were still present after 8 days. The results were considered positive for $98.2 \%$ of subjects after 16 days of treatment. Twenty eight children, i.e. $47.4 \%$, had no more signs of head lice and the others still presented at the end of evaluation the presence of unviable ova of Pediculus humanus capitis. Toxicity was evaluated by clinical examination of the subjects with head lice and of those people who had participated in the treatment and whose skin had been in contact with the emulsion. No adverse reaction was reported. Since decamethrin has been showed effective in the treatment of head lice, with no signs of toxicity, and also because of its low cost, the author concluded that decamethrin in useful for the control of Pediculus humanus capitis infestation.

UNITERMS: Pediculosis, therapy. Decamethrin. Pyrethrins.

\section{REFERENCIAS BIBLIOGRÁFICAS}

1. BOZZA, N.G. Ensayo clínico com un nuevo piretroide pediculicida: la decametrina. Pediatria, 3:152-3, 1979.

2. GOODMAN, S. \& GILMAN, G. The pharmacological basis of therapeutics. New York, Macmillan, 1980.

3. PATRUS, O.A. \& COSTA, P.U. Dermatoses por artrópodos. In: Neves, J. Doenças infecciosas e parasitárias em pediatria. Rio de Janeiro, Ed. GuanabaraKoogan, 1981.

4. PATRÚS, O.A. et al. Ensaio terapêutico duplo-cego com decametrina no tratamento da pediculose do couro cabeludo, Rev. bras. Med., 40:221-6, 1983.

5. PDR-Physicians' Desk Reference. 35th ed. Oradell, N.J. Medical Economics Co., 1981.

6. WORLD HEALTH ORGANIZATION. Expert Committee on Vector Biology and Control, Geneva, 1978. Geneva, 1979. (Techn. Rep. Ser., 634)

Recebido para publicação em 23/11/1984

Reapresentado em 09/05/1985

Aprovado para publicação em 15/05/1985 